\title{
Aviation Infrastructure Planning Through GP
}

\author{
Dr. Devendra Singh Hada \\ ${ }^{1}$ Department of Mathematics, Kautilya Institute of Technology and Engineering\& School of Management, \\ ISI - 16, RIICO Institutional Complex, Sitapura, Jaipur, Rajasthan, India.
}

\begin{abstract}
This paper makes an attempt to analyze the feasibility solutions with use of infrastructure planning for the purpose of project selection and finance arrangements. To analyze the project with respect to the sustainable indicators economic, social and environmental aspects of the project adequately. This research considers the decision framework for the sustainable transportation planning with appropriate use of sustainability indicators that help in prioritizing transportation plans with the help of goal programming optimization methodology. Paper makes an attempt to study the feasibility solutions with use of infrastructure planning for the purpose of project selection and finance arrangements. Through this paper suggested a goal programming model towards the resolution of a sustainable aviation transportation infrastructure plan. This model could help the decision maker with an ease in making effective decisions.
\end{abstract}

Keywords: aviation, goal programming, transportation, Multi-Criteria Decision Analysis

\section{INTRODUCTION}

Airlines are able to change their network structures overnight. The oil price, flu epidemics, and financial and economic woes further add to the unpredictability of aviation demand development. Combined with tensions between economic and environmental impacts, this makes airport strategic planning a challenging task. Airport strategic planning (ASP) focuses on the development of plans for the medium to long-term development of an airport. Strategic planning can be done in many different ways. In airports, the dominant approach is Airport infrastructure Planning (AIP). AIP boils down to forecasting the future demand and then drafting a blueprint for accommodating this demand.

The alternative approach to ASP is based on flexibility. It is recommended that plans should be able to manage with a range of demand levels. To realize this, a variety of techniques and approaches, such as real options, experimentation, flexible strategic planning, scenarios, and adaptive policymaking, have been put forward by researchers (Burghouwt and Huys [3], Neufville and Odoni [14], Neufville \& Barber [13], Kwakkel et al. [10]). The effectiveness of alternatives to AIP needs to be established before any alternative is used in practice. However, the validity and effectiveness of such new infrastructure planning approaches has not been explored in depth. Marchau et al. [12] have given the societal and economic importance of airports. To use an untested approach or idea in planning future airport developments is to expose the airport and its stakeholders to many risks.

Airports around the world operate in an increasingly uncertain environment. In today's air transport system, many major airports are already operating close their maximum throughput capacity. The consequence of this is that a large number of flights are delayed, which in many cases is due to the congestion on the airport surface. To enlarge airport capacity, runway and taxiway systems are being expanded. Jim and Chang [9] present airport as the interface between ground and air transport, comprised of airspace, airfield and passenger. Correia et al. [5] presents a global index for the evaluation of the level of service (LOS) of the operational components at an airport. Roling and Visser [15] describe a research effort pertaining to the development of a surface traffic automation system that will help controllers to better coordinate surface traffic movements related to arrival and departure traffic. In the process of probing for an optimum solution, towards the attainment of a sustainable transportation infrastructure, in the aviation industry, this could help the decision makers, with an appropriate resolution. In establishing the effectiveness of new infrastructure planning approaches one faces a methodological problem (Hansman et al. [7]). Bankes [1] give an operations research technique can be used as a method to overcome this problem.

A review of the Publication in airport modeling however reveals very few hybrid applications. Dijk et al. [6] presents and investigates a check-in problem at airport. Zografos and Madas [20] presented a theory that airport planning activities is to optimize the use of infrastructure and the cost of operation. Yan and Tang [17] investigated gate assignment as result to stochastic delays using integer programming with three heuristic methods. Chu [4] used goal programming for shift crew-duties in Hong Kong airport and Bauerle et al. [2] applied queuing model for the analysis of waiting time of arriving aircraft and the relation with capacity in airport with one or two runways. Yeh and Kuo [18] use fuzzy multi-attribute decision making technique to evaluate passenger service quality of 14 major AsiaPacific international airports using different surveys. Zografos and Madas [19] discussed in their study on development and demonstration of integrated support system for airport performance analysis. Tung et al. [16] 
presented a study, which coordinates the sustainable development system to plan an optimal strategy path to sustainable development in Taiwan. In this study a multi-objective integrated goal programming model suggested.

At the time of literature review and while analysis of real world problems, we observed a close linkage between sustainability and optimization resolutions by the use of goal programming technique (Jeon [8] and Liner [11]).

\section{AVIATION INDUSTRY}

Aviation is integral to the global economy and is one of the fastest growing industries in the world. However, aviation can be a significant contributor to local air pollution and ambient noise and is set to become a prominent cause of global warming if present growth trends continue. While the economic benefits of aviation are of the utmost importance and need to be retained, the potential for expansion in aviation could represent one of the main obstacles to environmentally sustainable development at the global level.

\section{Aviation and Sustainability}

Aviation brings several sustainability related benefits including:
A. Freedom of mobility;
B. Leisure
C. Employment
D. Major direct, secondary and indirect economic improvement
E. Global business links
F. Military security
G. Positive globalization effects.
It also provides costs including:
A. Finite resource depletion
B. Noise
C. Atmospheric emissions (air quality, ozone depletion, acid rain and climate change)
D. Waste products
E. Accidents

\section{Augmentation of Aviation's Sustainable Development}

At present, society's remit for aviation is to serve demand for air transport. This implies ongoing growth and as previously stated, whilst it is not possible to make aviation sustainable (in its present form) in the very long term, much can be and is being done to improve aviation's sustainability including:
A. Ensuring safety and security
B. Efficiently optimizing available capacity
C. Making decisions based on optimizing the balance between social, economic and environmental imperatives
D. Serving the need for mobility in a manner where the greatest overall benefit will arise, meeting the needs of stakeholders
E. Taking every opportunity to minimize adverse impacts and resource use by creating and operating more efficient ATM systems, equipment and technology
F. Avoid conflicting policy and regulations.

\section{Operations Deployment - Needs Planning}
A. Fly on routes and at altitudes to achieve minimum emissions.
B. Renegotiate en-route fuel reserve regulations.
C. Reduce airborne holding (stacking).
D. Install winglets at the end of wings to reduce drag.
E. Redesign hubs/schedules for less congestion - in the air and on the ground.
F. Campaign for expanded/improved airfield capacity to reduce congestion - in the air and on the ground.
G. Plug in to airport power when at gates instead of using aircraft engines.
H. Shutting down of engines during delays: such as taxi queuing and standing at the jet way.
I. With aircraft fuel, quality is also a key issue.

Failure involves more than coasting to the hard shoulder and waiting for the rescue truck. Whole consignments of jet fuel can be rejected on quality grounds, e.g., bacteria found in a tanker. Bio jet, a sustainable version of jet fuel, does not yet exist, although there is some activity in this area. Isolated pockets of interest are emerging, but claims that such a solution could be available within five years will require much greater government and 
industry support to become a reality. The challenge of new fuel is that any change to the fuel specification has to clear commercial, regulatory, and technical hurdles.

\section{PROBLEM DESCRIPTION}

The four priority strata are determined to reach the affected area as soon as possible with necessary constraints and variables. The expectations are taken to cover all possible factors affecting the sustainability of the aviation industry. The first stratum of priority, of attaining economic sustainability, includes four goals, of which one is to maximize the expected employment scenario with the maximized freedom of mobility. The attainment of the first stratum to the promising level is possible with minimization of cost of transport and maximization of the fuel efficiency. This would bring about the economic efficiency of the industry. The second stratum of priority is associated with increasing the operational efficiency to the maximum through minimization of aircraft turnaround such that the activities so performed are well synchronized giving preference to first activity that links to the other and then followed by the third. The goal one of this strata is appropriate traffic planning through maximization of viable promotional activities along with the maximization of customer services for the better operations. The third stratum of priority is to minimize the impacts on the natural resources caused due to the operation of the aviation industry. Thus we propose to minimize the impacts through minimization of land area devoted to aviation - air base, airport, operating heads, runways, etc.

Minimization of wastage created in the processing and an efficient effort to minimize the depletion of ecosystem, both contribute towards the realization of the third priority. The fourth priority goal is social improvement. It targets at the minimization of accidents and hazards occurred and having a tendency to take place in coming future as the first goal. For accomplishment of this goal, the industry needs to maximize the maintenance services and capitalize on the training activities. As goal two, the industry needs to focus on the maximization of cultural enrichment through more and better to and fro movement, along with maximized facilities to the frequent travelers.

\section{Targets}

Assessing aviation sustainability can be achieved using these categories:

i. Economic sustainability

ii. Operational efficiency

iii. Natural resource conservation

iv. Social improvement

Main Aim: Sustainability Maximization

Priority 1: Economic Sustainability

Goal 1: Freedom of mobility - maximize

i. Number of flight increase

ii. Travel per flight increased

Goal 2: Cost of transport - minimize

i. Number of seats per flight increase

ii. Cargo per flight increase

Goal 3: Fuel efficiency - maximize

i. Improved technology

ii. Air traffic management

Priority 2: Operational Efficiency

Goal 4: Traffic planning

i. Viable promotion maximize

ii. Customer service increase

Goal 5: Turn-around of Aircraft minimize

i. Cabin service - level 1

ii. $\quad$ Fuel refilling - level 2

iii. Maintenance - level 3

Priority 3: Natural Resource Conservation

Goal 6: Total land area devoted to aviation minimize

i. Minimization of occupancy of allied services at air field

Goal 7: Waste minimize

Goal 8: Eco-system depletion minimize

i. Tree plantation maximize 
ii. Usage of alternative fuel maximize

Priority 4: Social Improvement

Goal 9: Number of accidents and hazards to be minimize
i. Maintenance services to be increased
ii. Training activities increased

Goal 10: Cultural enrichment to be maximize

i. Number of flight increased

ii. Travel per flight increased

Goal 11: Facilities on board to be maximize

i. Frequent traveler incentives (attractive gift and service scheme) to be increased

Subject to the constraints:

i. Financial resources

ii. Area of land use

iii. Labor resources

\section{GOAL PROGRAMMING MODEL FORMULATION}

Formulating the main aims for sustainability maximization, bearing in mind the targets, according to their priorities by using goal programming model

Priority 1: Economic Sustainability

Priority 2: Operational Efficiency

Priority 3: Natural Resource Conservation

Priority 4: Social Improvement

$$
\begin{gathered}
\text { Minimize } \mathrm{z}=\mathrm{P}_{1}\left[\mathrm{~d}_{\mathrm{iFM}}^{-}+\mathrm{d}_{\mathrm{iCT}}^{+}+\mathrm{d}_{\mathrm{iFE}}^{-}\right]+\mathrm{P}_{2}\left[\mathrm{~d}_{\mathrm{iTP}}^{-}+\mathrm{d}_{\mathrm{iTA}}^{+}\right]+\mathrm{P}_{3}\left[\mathrm{~d}_{\mathrm{iTL}}^{+}+\mathrm{d}_{\mathrm{iW}}^{+}+\mathrm{d}_{\mathrm{iED}}^{+}\right] \\
+\mathrm{P}_{4}\left[\mathrm{~d}_{\mathrm{iAH}}^{+}+\mathrm{d}_{\mathrm{iCE}}^{-}+\mathrm{d}_{\mathrm{iFB}}^{-}\right]
\end{gathered}
$$

Subject to

\section{Economic goal}

$\sum_{\mathrm{j}=1}^{\mathrm{n}} \mathrm{A}_{\mathrm{ij}(\mathrm{FM})} \mathrm{X}_{\mathrm{j} \text { (FM) }}-\mathrm{d}_{\mathrm{iFM}}^{+}+\mathrm{d}_{\mathrm{iFM}}^{-}=\mathrm{b}_{\mathrm{i} \text { (FM) }}$

$\sum_{\mathrm{j}=1}^{\mathrm{n}} \mathrm{A}_{\mathrm{ij}(\mathrm{CT})} \mathrm{X}_{\mathrm{j}(\mathrm{CT})}-\mathrm{d}_{\mathrm{iCT}}^{+}+\mathrm{d}_{\mathrm{iCT}}^{-}=\mathrm{b}_{\mathrm{i}(\mathrm{CT})}$

$\sum_{j=1}^{n} A_{i j(F E)} X_{j(F E)}-d_{i F E}^{+}+d_{i F E}^{-}=b_{i(F E)}$

Operational efficiency goal

$\sum_{\mathrm{j}=1}^{\mathrm{n}} \mathrm{A}_{\mathrm{ij}(\mathrm{TP})} \mathrm{X}_{\mathrm{j}(\mathrm{TP})}-\mathrm{d}_{\mathrm{iTP}}^{+}+\mathrm{d}_{\mathrm{iTP}}^{-}=\mathrm{b}_{\mathrm{i}(\mathrm{TP})}$

$\sum_{\mathrm{j}=1}^{\mathrm{n}} \mathrm{A}_{\mathrm{ij}(\mathrm{TA})} \mathrm{X}_{\mathrm{j}(\mathrm{TA})}-\mathrm{d}_{\mathrm{iTA}}^{+}+\mathrm{d}_{\mathrm{iTA}}^{-}=\mathrm{b}_{\mathrm{i}(\mathrm{TA})}$

Natural resource conservation goal

$\sum_{\mathrm{j}=1}^{\mathrm{n}} \mathrm{A}_{\mathrm{ij}(\mathrm{TL})} \mathrm{X}_{\mathrm{j}(\mathrm{TL})}-\mathrm{d}_{\mathrm{iTL}}^{+}+\mathrm{d}_{\mathrm{iTL}}^{-}=\mathrm{b}_{\mathrm{i}(\mathrm{TL})}$

$\sum_{\mathrm{j}=1}^{\mathrm{n}} \mathrm{A}_{\mathrm{ij}(\mathrm{W})} \mathrm{X}_{\mathrm{j}(\mathrm{W})}-\mathrm{d}_{\mathrm{iW}}^{+}+\mathrm{d}_{\mathrm{iW}}^{-}=\mathrm{b}_{\mathrm{i}(\mathrm{W})}$

$\sum_{\mathrm{j}=1}^{\mathrm{n}} \mathrm{A}_{\mathrm{ij}(\mathrm{ED})} \mathrm{X}_{\mathrm{j}(\mathrm{ED})}-\mathrm{d}_{\mathrm{iED}}^{+}+\mathrm{d}_{\mathrm{iED}}^{-}=\mathrm{b}_{\mathrm{i}(\mathrm{ED})}$

Social improvement goal

$\sum_{\mathrm{j}=1}^{\mathrm{n}} \mathrm{A}_{\mathrm{ij}(\mathrm{AH})} \mathrm{X}_{\mathrm{j}(\mathrm{AH})}-\mathrm{d}_{\mathrm{iAH}}^{+}+\mathrm{d}_{\mathrm{iAH}}^{-}=\mathrm{b}_{\mathrm{i}(\mathrm{AH})}$

$\sum_{\mathrm{j}=1}^{\mathrm{n}} \mathrm{A}_{\mathrm{ij}(\mathrm{CE})} \mathrm{X}_{\mathrm{j}(\mathrm{CE})}-\mathrm{d}_{\mathrm{iCE}}^{+}+\mathrm{d}_{\mathrm{iCE}}^{-}=\mathrm{b}_{\mathrm{i}(\mathrm{CE})}$

$\sum_{j=1}^{n} A_{i j(F B)} X_{j(F B)}-d_{i F B}^{+}+d_{i F B}^{-}=b_{i(F B)}$

Area of land use

$\sum_{\mathrm{j}=1}^{\mathrm{n}} \mathrm{A}_{\mathrm{ij}(\mathrm{AU})} \mathrm{X}_{\mathrm{j}(\mathrm{AU})} \leq \mathrm{c}_{\mathrm{i}(\mathrm{AU})}$

Labor resource use

$\sum_{\mathrm{j}=1}^{\mathrm{n}} \mathrm{A}_{\mathrm{ij}(\mathrm{LU})} \mathrm{X}_{\mathrm{j}(\mathrm{LU})} \leq \mathrm{c}_{\mathrm{i}(\mathrm{LU})}$

Financial resources

$\sum_{\mathrm{j}=1}^{\mathrm{n}} \mathrm{A}_{\mathrm{ij}(\mathrm{FR})} \mathrm{X}_{\mathrm{j}(\mathrm{FR})} \leq \mathrm{c}_{\mathrm{i}(\mathrm{FR})}$

\section{Non-negativity constraint,}

$A_{i j(F M)}, A_{i j(C T)}, A_{i j(F E)} \geq 0, A_{i j(T P)}, A_{i j(T A)} \geq 0, A_{i j(T L)}, A_{i j(W)}, A_{i j(E D)} \geq 0$ 


$$
\begin{aligned}
& A_{i j(A H)}, A_{i j(C E)}, A_{i j(F B)} \geq 0, A_{i j(A U)}, A_{i j(L U)}, A_{i j(F R)} \geq 0, X_{j(F M)}, X_{j(C T)}, X_{j(F E)} \geq 0 \\
& X_{j(T P)}, X_{j(T A)} \geq 0, X_{j(A H)}, X_{j(C E)}, X_{j(F B)} \geq 0, X_{j(T L)}, X_{j(W)}, X_{j(E D)} \geq 0 \\
& X_{j(A U)}, X_{j(L U)}, X_{j(F R)} \geq 0, b_{i(F M)}, b_{i(C T)}, b_{i(F E)}, b_{i(T P)}, b_{i(T A)}, b_{i(A H)}, b_{i(C E)}, b_{i(F B)}, \\
& b_{i(T L)}, b_{i(W)}, b_{i(E D)} \geq 0, c_{i(A U)}, c_{i(L U)}, c_{i(F R)} \geq 0, d_{i F M}^{+}, d_{i F M}^{-}, d_{i C T}^{+}, d_{i C T}^{-}, d_{i F E}^{+}, d_{i F E}^{-} \geq 0 \\
& d_{i T P}^{+}, d_{i T P}^{-}, d_{i T A}^{+}, d_{i T A}^{-} \geq 0, d_{i A H}^{+}, d_{i A H}^{-}, d_{i C E}^{+}, d_{i C E}^{-}, d_{i F B}^{+} d_{i F B}^{-} \geq 0, d_{i T L}^{+}, d_{i T L}^{-}, d_{i W}^{+}, \\
& d_{i W}^{-}, d_{i E D}^{+}, d_{i E D}^{-} \geq 0
\end{aligned}
$$

\section{The following notations are used in the model formulation:}

\section{Parameters}

$d_{i}^{-}=$negative deviation if $b_{i}$ goals are under achieved

$d_{i}^{+}=$positive deviation if $b_{i}$ goals are over achieved

$b_{i(F M)}, b_{i(C T)}, b_{i(F E)}, b_{i(T P)}, b_{i(T A)}, b_{i(A H)}, b_{i(C E)}, b_{i(F B)}, b_{i(T L)}, b_{i(W)}, b_{i(E D)}$, these are the aspirations (target value) or threshold levels for the $\mathrm{i}^{\text {th }}$ goals and taking short name of goals in subscript form. $A_{i j(F M)}, A_{i j(C T)}, A_{i j(F E)}, A_{i j(T P)}, A_{i j}(T A), A_{i j(T L)}, A_{i j(W)}, A_{i j(E D)}$,

$A_{i j(A H)}, A_{i j(C E)}, A_{i j(F B)}, A_{i j(A U)}, A_{i j(L U)}, A_{i j(F R)}$ these are the marginal contribution of decision variables which will be determined according to goal and short name of goals are taken in subscript form.

\section{Available resources}

In equations $(\mathbf{1 3}, \mathbf{1 4}, \mathbf{1 5})$ the right hand side constants are taken as-

$\mathrm{C}_{\mathrm{i}(\mathrm{AU})}$ : is representing total area of land available

$\mathrm{c}_{\mathrm{i}(\mathrm{LU})}$ : is representing total labor resource for use available

$\mathrm{c}_{\mathrm{i}(\mathrm{FR})}$ : is representing total financial resource for use available

\section{Decision variables}

$\mathrm{X}_{\mathrm{j}(\mathrm{FM})}, \mathrm{X}_{\mathrm{j}(\mathrm{CT})}, \mathrm{X}_{\mathrm{j}(\mathrm{FE})}$ are the decision variables represent freedom of mobility, cost of transport and fuel efficiency for achieving economic efficiency. $\mathrm{X}_{\mathrm{j}(\mathrm{TP})}, \mathrm{X}_{\mathrm{j}(\mathrm{TA})}$ are the decision variables represent traffic planning, turnaround of aircraft for achieving operational efficiency. $\mathrm{X}_{\mathrm{j}(\mathrm{AH})}, \mathrm{X}_{\mathrm{j}(\mathrm{CE})}, \mathrm{X}_{\mathrm{j}(\mathrm{FB})}$ are the decision variables represent number of accidents and hazards, cultural enrichment and facilities on board for achieving social improvement. $\mathrm{X}_{\mathrm{j}(\mathrm{TL})}, \mathrm{X}_{\mathrm{j}(\mathrm{W})}, \mathrm{X}_{\mathrm{j}(\mathrm{ED})}$ are the decision variables for represent land area devoted, waste and ecosystem depletion for achieving natural resource conservation.

$\mathrm{X}_{\mathrm{j}(\mathrm{FM})}, \mathrm{X}_{\mathrm{j}(\mathrm{CT})}, \mathrm{X}_{\mathrm{j}(\mathrm{FE})}, \mathrm{X}_{\mathrm{j}(\mathrm{TP})}, \mathrm{X}_{\mathrm{j}(\mathrm{TA})}, \mathrm{X}_{\mathrm{j}(\mathrm{AH})}, \mathrm{X}_{\mathrm{j}(\mathrm{CE})}, \mathrm{X}_{\mathrm{j}(\mathrm{FB})}, \mathrm{X}_{\mathrm{j}(\mathrm{TL})}, \mathrm{X}_{\mathrm{j}(\mathrm{W})}, \mathrm{X}_{\mathrm{j}(\mathrm{ED})}$ these can be divided into the decision variables in terms of sub goals; number of flight increase, travel per flight increased, number of seats per flight increase, cargo per flight increase, improved technology, air traffic management, viable promotion maximize, customer service increase, cabin service - level 1, fuel refilling - level 2, maintenance - level 3, minimization of occupancy of allied services at air field, tree plantation maximization, usage of alternative fuel maximization, maintenance services to be increased, training activities increased, frequent traveler incentives (attractive gift and service scheme to be increased) in this same manner the contribution of each decision variable converted into matrix form $A_{i j}$ for the $i=1,2, \ldots, m$ and $j=1,2, \ldots, n$, while the value of $m$ depends on the subgoals of the required goal. From the equation $(13,14,15)$ the decision variables for the other constraints are define as:

$\mathrm{X}_{\mathrm{j}(\mathrm{AU})}$ : is area of land use for the $\mathrm{j}^{\text {th }}$ activity, $\quad \mathrm{X}_{\mathrm{j}(\mathrm{LU})}$ : is Labor use for the $\mathrm{j}^{\text {th }}$ activity

$\mathrm{X}_{\mathrm{j}(\mathrm{FR})}$ : is finance used for the $\mathrm{j}^{\text {th }}$ activity

\section{SOLUTION}

The above formulated problem can be solving through simplex method using Tora, or Lingo computer software package.

\section{DISCUSSION AND CONCLUSION}

The model can prove to be a decisive step for the managers towards the attainment and determination of the economic, social improvement, operational efficiency and natural environment goals. Thus preparing a sustainable transport project w.r.to the aviation industry which will fulfill the goals of the sustainability indicators. This paper presents a set of aviation transport planning indicators along with a goal programming approach that may be used to arrange the infrastructure investments in an order of precedence so as to accomplish the sustainability targets. The difficulty appeared while this course of study could be exact ascertainment of the intensity of the area of decision variables. Hence the documentation of the decision variables might not accommodate all the available \& possible factors affecting or influencing the decision variable. Presented goal programming formulation based on some practical data 
being gathered from actual airports site, with the help of a consultancy company those providing ground handling consultancy of all civil aircrafts.

\section{REFFERENCE}

[1] Bankes, S., Exploratory modeling for policy analysis, Operations Research, INFORMS, Vol.4 (3) (1993), pp. $435-449$.

[2] Bauerle, N., Engelhardt-Funke, O. and Kolonko, M., On the waiting time of arriving aircrafts and the capacity of airports with one or two runways, European Journal of Operational Research, Elsevier, Vol.177(2)(2007), pp.1180-1196.

[3] Burghouwt, G. and Huys, M., Deregulation and the consequences for airport planning in Europe, Network City and Landscape, DISP, Zurich, Vol. 154(3) (2003), pp. 37-45.

[4] Chu, S.C.K., Generating, scheduling and shift crew-duties: application at the Hong Kong international airport, European Journal of Operational Research, Elsevier, Vol.177 (3) (2007), pp.1764-1778.

[5] Correia, A.R., Wirasinghe, S.C. and Barros, A.G., A global index for level of service evaluation at airport passenger terminals, Transportation Research part E: Logistics and Transportation Review, Elsevier, Vol.44 (4) (2008), pp.607-620.

[6] Dijk, Van N.M. and Sluis,Van der E., Check-in computation and optimization by simulation and IP in combination, European Journal of Operational Research, Elsevier, Vol.171 (2) (2006), pp. 1152-1168.

[7] Hansman, R. J., Magee, C., Neufville, R.D., Robins, R. and Roos, D., Research agenda for an integrated approach to infrastructure planning, design and management, International Journal of Critical Infrastructures, Inderscience, Vol.2 (2-3) (2005), pp. 146-159.

[8] Jeon, Christy Mihyeon, Incorporating Sustainability into Transportation Planning and Decision Making: Definitions, Performance Measures and Evaluation, Ph.D Thesis, Georgia Institute of Technology, 2007.

[9] Jim, H.K. and Chang, Z.Y., An airport passenger terminal simulator: A planning and design tool, Simulation Practice and Theory, Elsevier, Vol.6 (4) (1998), pp. 387-396.

[10] Kwakkel, J. H., Wijnen, R. A. A., Walker, W. E. and Marchau, V. A. W. J., A fast and simple model for a quick scan of airport performance, Paper presented at the 13th Air Transport Research Society World Conference, Abu Dhabi, United Arab Emirates, 6-10 July, 2009.

[11] Liner, B., Goal Programming for Sustainability in Total Water Management, Ph.D Thesis, George Mason University, Fairfax, VA, 2009.

[12] Marchau, V. A. W. J., Walker, W. E. and Duin, Van R., An adaptive approach to implementing innovative urban transport solutions, Transport Policy, Elsevier, Vol.1 (6) (2009), pp. 405-412.

[13] Neufville, De R. and Barber, J., Deregulation induced volatility of airport traffic, Transportation Planning and Technology, Routledge, Taylor \& Francis, Vol.16 (2) (1991), pp. 117-128.

[14] Neufville, De R. and Odoni, A., Airport Systems: Planning, Design and Management, McGraw-Hill, New York, 2003.

[15] Roling, P. C. and Visser, H. G., Optimal airport surface traffic planning using mixed-integer linear programming, AIAA Aviation Technology, Integration and Operations (ATIO) Conference, Denver, 2003.

[16] Tung, Ling Hui, Tsai, Tang Hsien, Wei, Ming Yi, Wei, D., Lee, C. M., Using DSR indicator system to evaluate Taiwan’s sustainable development, International Journal of Global Energy Issues, Vol. 22(2/3/4) (2004), pp. 242 - 258

[17] Yan, S. and Tang, C.H., A heuristic approach for airport gate assignments for stochastic flight delays, European Journal of Operational Research, Elsevier, Vol. 180(2) (2007), pp. 547-567.

[18] Yeh, C.H. and Kuo, Y.L., Evaluating passenger service of Asia-Pacific International airports, Transportation Research Part E: Logistics and Transportation Review, Elsevier, Vol.39 (1) (2003), pp.35-48.

[19] Zografos, K.G. and Madas, M.A., Development and demonstration of integrated support system for airport performance analysis, Transportation Research Part C: Emerging Technologies, Elsevier, Vol.14 (1) (2006), pp. 1-17.

[20] Zografos, K.G. and Madas, M.A., Airport capacity vs. demand: Mismatch or mismanagement, Transportation Research Part A: Policy and Practice, Elsevier, Vol.42 (1) (2008), pp.203-226. 